\title{
Effects of Bedrock Landsliding on Cosmogenically Determined Erosion Rates
}

\author{
Nathan Niemi ${ }^{\mathrm{a}}$, Mike Oskin ${ }^{\mathrm{b}}$, Douglas Burbank ${ }^{\mathrm{a}}$ and Arjun Heimsath ${ }^{\mathrm{c}}$ \\ anstitute for Crustal Studies, University of California, Santa Barbara, CA 93106 USA \\ bDepartment of Geological Sciences, University of North Carolina, Chapel Hill, NC 27599 USA

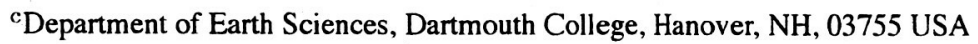

\begin{abstract}
The successful quantification of long-term erosion rates underpins our understanding of landscape formation, the topographic evolution of mountain ranges, and the mass balance within active orogens. The measurement of in situ-produced cosmogenic radionuclides (CRNs) in fluvial and alluvial sediments is perhaps the method with the greatest ability to provide such longterm erosion rates. In active orogens, however, deep-seated bedrock landsliding is an important erosional process, the effect of which on CRN-derived erosion rates is largely unquantified. We present a numerical simulation of cosmogenic nuclide production and distribution in landslide-dominated catchments to address the effect of bedrock landsliding on cosmogenic erosion rates in actively eroding landscapes. Results of the simulation indicate that the temporal stability of erosion rates determined from CRN concentrations in sediment decreases with increased ratios of landsliding to sediment detachment rates within a given catchment area, and that larger catchment areas must be sampled with increased frequency of landsliding in order to accurately evaluate long-term erosion rates. In addition, results of this simulation suggest that sediment sampling for CRNs is the appropriate method for determining long-term erosion rates in regions dominated by mass-wasting processes, while bedrock surface sampling for CRNs is generally an ineffective means of determining long-term erosion rates. Response times of CRN concentrations to changes in erosion rate indicate that climatically driven cycles of erosion may be detected relatively quickly after such changes occur, but that complete equilibration of CRN concentrations to new crosional conditions may take tens of thousands of years. Simulation results of CRN erosion rates are compared with a new, rich dataset of CRN concentrations from the Nepalese Himalaya, supporting conclusions drawn from the simulation.
\end{abstract}

\section{Introduction}

The successful quantification of long-ierm erosion rates underpins our understanding of landscape formation, the topographic evolution of mountain ranges, and the mass balance within active orogens [1]. Observed changes in long-term erosion rates are often considered proxies for changes in the climatic or tectonic boundary conditions that control landscape evolution. As the importance of long-term erosion rates to unraveling significant geomorphic and tectonic problems has become clear, a widely applicable means of measuring long-term surface denudation rates has been sought. The measurement of in situproduced cosmogenic radionuclides (CRNs) in fluvial and alluvial sediments has been shown to yield spatially averaged erosion rates, and has become perhaps

*Also at: Division of Geological and Planetary Sciences, California Institute of Technology. Pasadena, CA 91125 USA.

${ }^{\dagger}$ Also at: Department of Geological Sciences, University of California, Santa Barbara, CA 93106 USA. the method with the greatest applicability in measuring erosion rates over $10^{3}-10^{5}$ years and across a wide variety of landscapes and erosional processes [2-6]. Most existing studies that utilize CRN-derived erosion rates have focused on regions with fairly spatially and temporally homogeneous erosion rates. Here we present a simulation to explore the effects of bedrock landsliding on cosmogenic erosion rates, and potential for exploiting cosmogenic nuclides to measure erosion rates in rapidly eroding, active orogens.

Large bedrock landslides incise to depths greater than one or more attenuation lengths of cosmic rays, thus mobilizing sediments with little or no cosmogenic nuclide abundance (Fig. 1). For example, based on empirical relationships of landslide depth to area [7], a landslide with a radius of just 10 meters will incise to $\sim 100 \mathrm{~cm}$, below one attenuation depth for spallogenic nuclide production. An extraordinarily large slide may incise to a maximum depth of several tens of meters, below one attenuation depth for 
A

Steady-state Erosion

Time

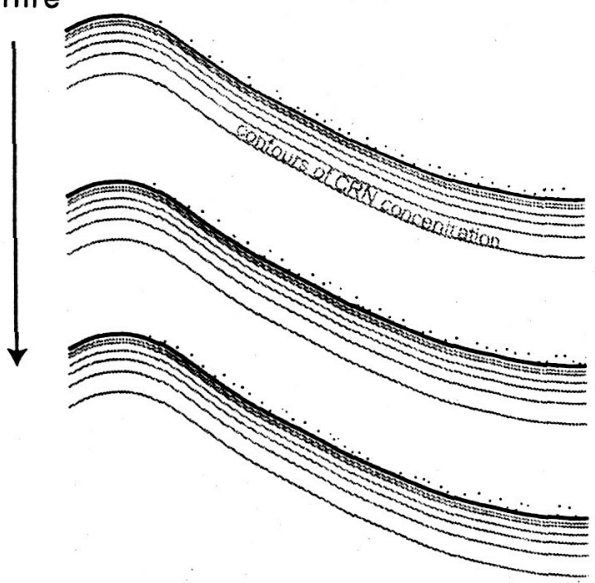

B Landslide-dominated Erosion

Time

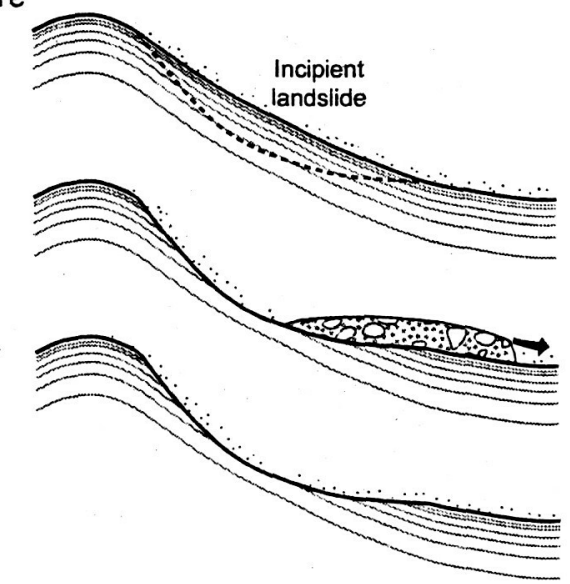

Figure 1. Cartoon showing the effects of landslides on surface cosmogenic nuclide concentrations. A) Homogeneous CRN surface concentration and sediment volume and concentration during steady-state erosion. B) Heterogeneous surface CRN concentration and heterogeneous sediment volume and CRN concentration during landslide-dominated erosion.

muogenic nuclide production. In catchments where deep landslides have recently occurred, the addition of nuclide-poor landslide detritus to the fluvial system will dilute the CRN concentration in the fluvial sediment, yielding apparently higher erosion rates. For example, samples from low-order fluvial catchments in the Nepalese Himalaya yield 'erosion rates' determined from cosmogenic nuclides that range from 0.01 to $0.5 \mathrm{~mm} / \mathrm{yr}$, even along the same ridge crest (Heimsath, in prep.). Similar results are reported from the San Bernardino Mountains in southern California, where 'erosion rates' along a landslide-dominated escarpment vary from $<0.3$ to $>2.7 \mathrm{~mm} / \mathrm{yr}$, while rates from an adjacent region dominated by sediment detachment are on the order of hundredths of $\mathrm{mm} / \mathrm{yr}$ [8]. Whereas such variability may be expected for data sets that are focused on small, steep catchments in actively deforming mountain belts, it does not explain how in situ-produced CRNs may be utilized to understand the rates of erosion in regions affected by both sediment detachment and landsliding processes.

Here we address the effects of bedrock landsliding on CRN-derived erosion rates from bedrock and fluvial samples in an attempt to answer several basic questions: As the rate of landsliding increases, how are CRN concentrations in fluvial sediment affected? Can reliable CRN erosion rates be derived from fluvial sediment or bedrock samples when landsliding is the dominant erosional process? Over what spatial scales do fluvial systems integrate the effects of landsliding? What timescales are required for CRN concentrations to respond to changes in erosion rates? We present the results of a numerical simulation of cosmogenic nuclide production and erosional removal in landslide-dominated catchments to assess these questions. A series of simulations with varying sediment detachment and landslide erosion rates are used to create statistical populations of CRN-derived erosion rates for both 'sediment' and 'bedrock' samples for a theoretical landscape. Finally, simulated distributions of CRN-derived ages are compared to a new, rich data set of CRN-derived erosion rates from the Nepalese Himalaya. 


\section{Numerical Simulation}

The numerical simulation is based on actual digital elevation data, and simulates the production of cosmogenic nuclides at each model cell, the removal of material through sediment detachment, the removal of material by landsliding, and the radioactive decay of cosmogenic nuclides. A Geographic Information System (GIS; in this case ArcInfo) is used for the backbone of the simluation. Model initialization, data assimilation, and data output are all controlled through the GIS using Arc Macro Language (AML). Computationally intensive portions of the model are passed from the GIS to customized Perl modules for computational efficiency. The three main functionalities of the simulation are described in greater detail below.

\subsection{Cosmogenic Nuclide Production}

Prior to running the landslide simulation model, cosmogenic nuclide production rates must be calculated for each cell in the model. Calculation of these rates begins with a geo-referenced digital elevation model (DEM) of the study area of interest. For each cell in the digital elevation model, cosmogenic production scaling factors are calculated within the GIS based on cell altitude and latitude following $[9,10]$. Further corrections to cosmogenic production are applied by calculating the topographic shielding at each point in the DEM. For each cell in the DEM, the vertical angle to to every other cell is calculated. These values are binned into $5^{\circ}$ radial bins, and the maximum vertical angle in each bin is used to approximate the horizon angle for that bin. The topographic shielding factor for each bin is derived from the horizon angle using a published methodology [11]. The altitude, latitude, and topographic shielding factors are combined within the GIS system to produce an output array of cosmogenic production scaling factors. This array is then multiplied by the high-latitude, sea-level production rate of the cosmogenic nuclide of interest to create an array of cosmogenic production rates. In this case, we have chosen to model ${ }^{10} \mathrm{Be}$ and selected a production rate of 5.3 atoms $/ \mathrm{g} / \mathrm{yr}$ [12]. This array of ${ }^{10} \mathrm{Be}$ production rates is preserved for use through the rest of the model run.

\subsection{Model Initialization}

Model initialization consists of two separate actions: i) preparing the model for data gathering and assimilation and ii) calculating an initial surface cosmogenic nuclide concentration to start the landslide model. The first of these two tasks is the most timeintensive and must be performed separately for each DEM on which this model is run. Using the hydrologic functions available in a GIS, watersheds within the model area are delineated. A variety of firstthrough highest-order watersheds are selected and saved for later use in data analysis. Additionally, 100 random points are generated across the model space at which to track cosmogenic nuclide concentrations in bedrock and erosional removal of material. After the data gathering initialization steps are complete, an input cosmogenic surface nuclide concentration array must be calculated for input to the landslide portion of the model. We have chosen to input a surface concentration grid that represents the steady-state concentration of ${ }^{10} \mathrm{Be}$ at the sediment detachment rate specified for the model run. The sediment detachment rate is limited by the rate at which rock can be converted to soil or regolith, and is taken to be less than $0.3 \mathrm{~mm} / \mathrm{yr}$ [13]. The surface concentration $(N)$ is calculated for each point in the model following this equation:

$\left.N^{10} \mathrm{Be}=\frac{P^{10} \mathrm{Be}}{\left(\lambda_{10} B e+E / \Lambda\right)}\left(1-e^{-\left(\lambda_{10} B e\right.}+E / \Lambda\right) t\right)$

Where $N^{10} \mathrm{Be}$ and $P^{10} \mathrm{Be}$ are the concentration (atoms $/ \mathrm{g}$ ) and production rate (atoms $/ \mathrm{g} / \mathrm{yr}$ ) of ${ }^{10} \mathrm{Be}$, respectively; $\lambda_{10} \mathrm{Be}$ is the decay constant of ${ }^{10} \mathrm{Be}$ $\left(\mathrm{yr}^{-1}\right) ; E$ is the erosion rate (here equivalent to the sediment detachment rate), in $\mathrm{g} / \mathrm{cm}^{2} / \mathrm{yr} ; \Lambda$ is the neutron attenuation length in rock, in $\mathrm{g} / \mathrm{cm}^{2}$; and $t$ is time (yr). This initial concentration array is saved for input into future model runs.

\subsection{Landslide Simulation}

The landslide simulation portion of the model takes as input the surface cosmogenic nuclide concentration array calculated in the previous step, and the cosmogenic production rate array calculated in the first model step. This portion of the model is iterated. At the end of each iteration, two arrays are output, a depth array which contains the sum of all sediment removed by erosion, due to both sediment detachment and landsliding, and a surface concentration ar- 
ray that contains the surface cosmogenic nuclide concentration at each model cell after erosional removal of material, cosmogenic ingrowth and radioactive decay. The individual steps are detailed below.

\subsubsection{Cosmogenic ingrowth and decay}

The first step in the iteration of the landslide model is to add cosmogenic nuclide ingrowth for one model time step $(t)$ to the input surface cosmogenic nuclide concentration array. Given, for each cell in the model, an initial surface cosmogenic nuclide concentration, $N_{i}^{10} \mathrm{Be}$, and a surface cosmogenic nuclide production rate, $P^{10} \mathrm{Be}$, a resultant surface cosmogenic nuclide concentration, $N_{r}^{10} \mathrm{Be}$, produced by cosmic ray bombardment and removal by radioactive decay can be calculated by:

$N_{r}^{10} \mathrm{Be}=\left(N_{i}^{10} \mathrm{Be}+P^{10} \mathrm{Be} \cdot t\right) e^{-\lambda_{10} e^{t}}$

The new surface concentration, $N_{r}^{10} \mathrm{Be}$, replaces the initial value in the surface concentration array.

\subsubsection{Sediment detachment}

For each model run, a sediment detachment rate, $E_{s}$ is specified. This rate represents the spatially homogeneous erosional removal of material from the land surface, limited by weathering and soil production processes (e.g. grussification in granitic terranes). For each model time step ( $t)$, a depth equal to $E_{s} \times t$ is removed from the landscape and added to the depth grid. This material is always removed from the upper surface of the topography, and therefore has the highest concentration of CRNs.

\subsubsection{Landslides}

After removal of material by sediment detachment, the model is populated with landslides. Landslides are assumed to obey a power-law frequencymagnitude relationship $[7,14,15]$. Based on this assumption, populations of landslides in the model can be derived from four parameters: $\beta$, the power-law exponent for landslide frequency-magnitude relationship, $A_{\min }$, the minimum landslide area considered in the model, $A_{\max }$, the maximum landslide area considered in the model, and $E_{l s}$, the average rate of erosion by landsliding over the model area. Although short-term landslide erosion rates fluctuate due to the episodicity of landslides, the average rate of erosion by landsliding is produced through the powerlaw frequency-magnitude relationship over time (Fig.

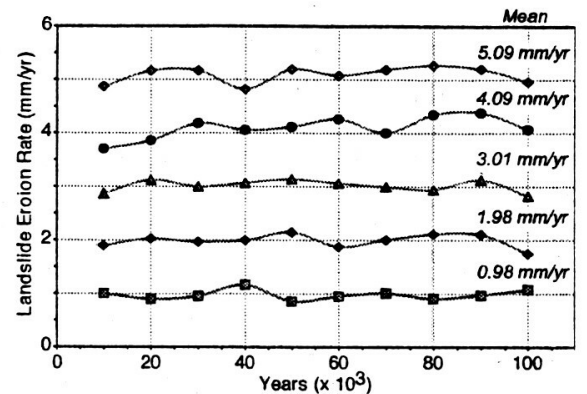

Figure 2. Comparison of output model landslide erosion rates with prescribed landslide erosion rates, averaged over 10,000 year time steps. Mean erosion rates for the 100,000 year model run are shown at the right of the figure. Short term variations in landslide erosion rate are due to random distribution of slide size; long term landslide erosion rates retum input erosion rates $\pm 3 \%$.

2). Complete derivations of landslide frequencymagnitude distributions in the model space are given in Appendix A. For each model timestep, a landslide distribution is generated, and the landslides are randomly distributed over the model space. The total amount of material removed by landsliding from each model cell during the timestep is then calculated. The total depth of material removed by landsliding is added to the depth of material removed by sediment detachment (see Appendix A).

\subsubsection{Surface concentration}

Once the depth array is tabulated, the surface cosmogenic nuclide concentration is recalculated to reflect the depth of material removed from each model cell. Assuming, for simplification, a constant rock density $(\rho)$ in the model of $2.65 \mathrm{~g} / \mathrm{cm}^{3}$, and a cosmogenic ray attenuation length in this rock $(\Lambda)$ of 150 $\mathrm{cm}^{2} / \mathrm{g}$, a final surface cosmogenic nuclide concentration at the end of the timestep, $N_{f}^{10} \mathrm{Be}$, can be calculated for each cell based on the cosmogenic concentration following ingrowth, $N_{r}^{10} \mathrm{Be}$, above, and the depth of material, $D$, removed from the cell during the timestep:

$N_{f}^{10} \mathrm{Be}=N_{r}^{10} \mathrm{Be} \cdot e^{-D(\rho / \Lambda)}$

The value $N_{f}^{10} \mathrm{Be}$ is stored for each cell in the surface concentration array. At this point, this array is saved 
for data extraction, as described in the next section, and then re-opened as the initial surface concentration grid for the next iteration step of the landslide portion of the model.

\subsection{Data Extraction}

At a user-specified sampling interval, the depth array and surface concentration array are passed back to the GIS, and data are extracted from each array to simulate two potential cosmogenic nuclide sampling methods: surface exposure age dating and stream sediment sampling.

\subsubsection{Surface exposure age dating}

To simulate the effects of landsliding on surface age exposure dating, at each sampling interval, the depth of material removed from, and the final surface concentration at, each of 100 randomly generated points across the model are recorded. From these data, a volumetric erosion rate $\left(E_{v}\right)$ for this sampling interval is calculated by dividing the depth of material removed $(D)$ by the model time step ( $t$; recall that $D$ includes both continual removal of rock by sediment detachment and episodic landsliding). Additionally, a cosmogenic erosion rate $\left(E_{c}\right)$ is calculated, for each point using the standard assumption of steady-state erosion [16]:

$E_{c}=\frac{\Lambda}{\rho}\left(\frac{P^{10} \mathrm{Be}}{N_{f}^{10} \mathrm{Be}}-\lambda_{10} B e\right)$

Both volumetric and cosmogenic surface-exposureage erosion rates, along with the depth and surface concentration information, are stored in a database file. Data can be extracted after the completion of the model run to analyze the variation in volumetric and cosmogenic erosion rates at a given point through time, or data from all points can be assimilated and a probability density function (PDF) for either erosion rate can be calculated.

\subsubsection{Stream sediment sampling}

In addition to surface age exposure dating, cosmogenic nuclide concentrations in stream sediments can be used to estimate average upstream erosion rates. To test the effects of landsliding on such estimates of erosion rates, the model also extracts data by watersheds. At each sampling interval, the following procedures are carried out for each watershed of interest. A volumetric erosion rate $\left(E_{v}\right)$ is calculated by summing the total depth of material removed from the watershed and dividing it by the watershed area multiplied by the model time step. Second, a cosmogenic erosion rate $\left(E_{c}\right)$ for the watershed is calculated. To calculate this erosion rate, first the concentration of the cosmogenic nuclide of interest in the eroded sediment must be determined. Using the depth array and surface concentration array, the average nuclide concentration in the eroded material at each model cell, $N_{D}^{10} \mathrm{Be}$, can be calculated as follows:

$N_{D}^{10} \mathrm{Be}=N_{f}{ }^{10} \mathrm{Be} \cdot \Lambda\left(1-e^{-D(\rho / \Lambda)}\right)$

The concentration of cosmogenic nuclides in the sediment removed from the watershed, $N_{S}^{10} \mathrm{Be}$, then, is:

$N_{S}^{10} \mathrm{Be}=\sum N_{D}^{10} \mathrm{Be} / \sum D$

The erosion rate derived from the cosmogenic nuclide concentration in the material removed from the watershed is then calculated as in Eqn. 4, where $P^{10} \mathrm{Be}$ would represent the watershed-averaged production rate (derived from the GIS-based production calculations), and $N_{f}^{10} \mathrm{Be}$ would be replaced with $N_{S}^{10} \mathrm{Be}$. Both volumetric and cosmogenic erosion rates are recorded to database files, and saved for later analysis.

\subsubsection{Simplifications and assumptions}

It should be noted that the model outlined above makes several simplifying assumptions regarding sediment production and transport. With regards to sediment detachment and transport, this is assumed to occur at a homogeneous rate across the entire model, although in reality the rate at which these processes act on the scale of our model are controlled by local slope and lithology. Landslides are also randomly placed across the landscape, with no considerations for hillslope and aspect. Second, the model contains no provision for sediment storage. All material derived from landsliding is assumed to pass through the model within the timestep in which the landslide occurred (100 years for the models discussed here). Third, the model is intended to produce a population of cosmogenic and volumetric erosion rates for statistical analysis. Erosion and landslides occur through 'time' to produce a variety of surface CRN concentrations that could potentially be sampled; however, this model is not a landscape evolution model. During the course of the model run, the model landscape 
Table 1

Statistics for basins tracked in the model.

\begin{tabular}{lcc}
\hline Basin Order & $\begin{array}{c}\text { Number of } \\
\text { Basins }\end{array}$ & $\begin{array}{c}\text { Mean Area } \\
\left(\mathrm{km}^{2}\right)\end{array}$ \\
\hline First & 30 & 0.1 \\
Second & 6 & 0.6 \\
Third & 5 & 2.3 \\
Fourth & 4 & 8.4 \\
Fifth & 1 & 69.0 \\
\hline
\end{tabular}

surface does not evolve, and shielding effects or absolute elevation changes that in reality would alter CRN production rates are not considered. Finally, the role of muogenic production is not explicitly considered in this simulation. The greater attenuation length of muons would likely have the effect of moderating to some extent the surface nuclide concentration in the wake of small- to moderate-sized landslides, but large landslides, which carry the majority of the erosional load, will incise more deeply than the attenuation depth of muons, and thus would have a negligible effect on the model.

\section{Model Results}

To examine the model, we simulated the effects of landsliding on cosmogenic nuclide equilibrium, and associated CRN-derived and volumetrically calculated erosion rates for the San Antonio Creek catchment, located in the eastern San Gabriel Mountains of southern California (Fig. 3). It is a small $\left(\sim 70 \mathrm{~km}^{2}\right)$, mountainous catchment, selected in part because of the availability of high-quality digital elevation model (DEM) data over the region (30-meter resolution), and in part because a significant amount of work exists describing the geomorphology and neotectonics of the region. Low-temperature thermochronologic data indicate that the eastern San Gabriel Mountains are being exhumed at a rate of $\sim 0.3-1 \mathrm{~mm} / \mathrm{yr}$ [1719], while geomorphic and geologic studies indicate that landsliding is a prevalent mechanism of erosion in this watershed $[20,15]$. In fact, both a landslide frequency-magnitude exponential scaling factor $(\beta)$ and a long-term average erosion rate have been determined for this region [15]. Interestingly, in the San

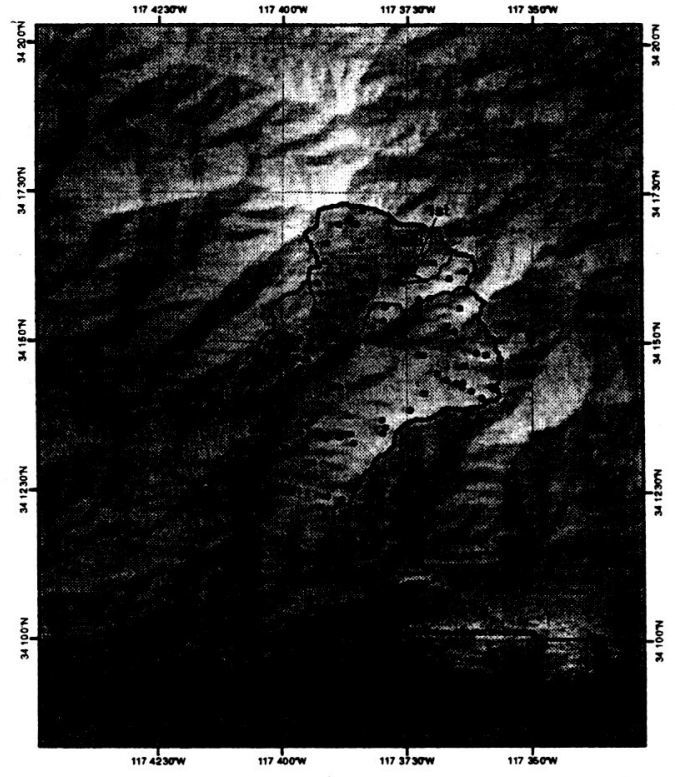

Figure 3. Shaded relief map of the San Antonio Creek watershed, San Gabriel Mountains, California. The full watershed is outlined with a heavy black line, while representative smaller order watersheds are indicated with a lighter black line. Random 'bedrock' sampling points (discussed in the text) are shown as black dots.

Gabriel Mountains, $\beta=1.1$, similar to results from the Southern Alps of New Zealand [7]. When $\beta$ is less than 1.5 , large, but infrequent landslides dominate the overall sediment flux from a catchment. As such, this watershed potentially provides a natural laboratory to study the effects of landsliding on CRN-derived erosion rates, and for comparison with and calibration of the numerical model.

Within the San Gabriel Mountains, San Antonio Creek is a fifth-order stream. The San Antonio Creek watershed was divided into 46 sub-basins that were tracked as part of this simulation, from which modeled sediment-derived CRN erosion rates were calculated (examples shown in Fig. 3; basin statistics are listed in Table 1). In addition to the sub-basins, 100 points were randomly distributed across the model space to serve as simulated bedrock CRN sampling localities (Fig. 3). For San Antonio Creek, sedi- 


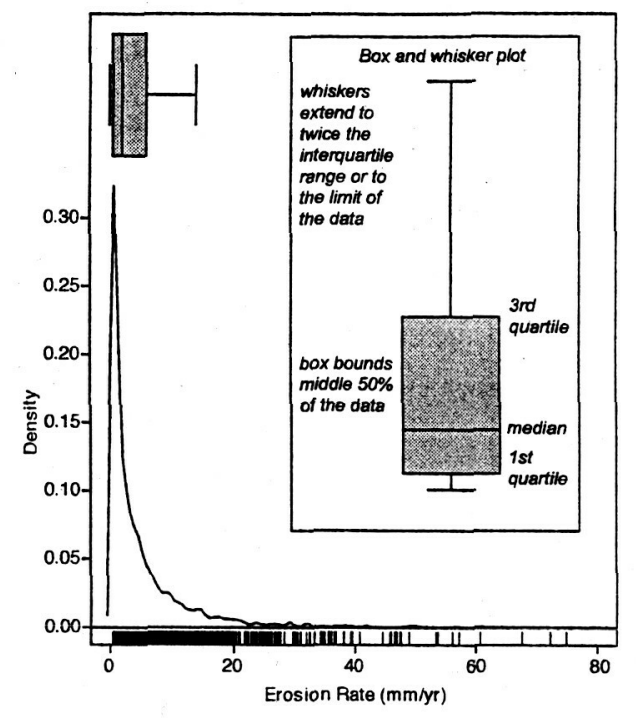

Figure 4. Example of a box-and-whisker piot to graphically display the statistical distribution of a non-Gaussian data set. A probability density function (PDF) and boxplot are shown for actual model results of cosmogenic erosion rates from first-order basins with a sediment detachment rate of $0.1 \mathrm{~mm} / \mathrm{yr}$ and a total erosion rate of $10 \mathrm{~mm} / \mathrm{yr}$. The distribution of erosion rates is plotted across the bottom of the graph as a series of vertical black hash marks.

ment detachment rates of $0.01,0.1$ and $0.3 \mathrm{~mm} / \mathrm{yr}$ were selected, spanning the range of observed sediment detachment rates in the Transverse Ranges [8] to the most rapid known rates of rock-to-regolith conversion [13]. For each of the three sediment detachment rates, simulations of total erosion rates of 1 , 5 , and $10 \mathrm{~mm} / \mathrm{yr}$ were run. The rate of erosion by landsliding in each simulation run is the difference between the total erosion rate and the sediment detachment rate. Once the simulation was equilibrated to the imposed erosion rate, the simulation ran for 100,000 yrs in 100 yr timesteps. Simulated cosmogenic nuclide concentrations were sampled from the 46 tracked catchments and the 100 bedrock locations every 1000 years, yielding 100 data points per analysis element (either catchment or bedrock location).

Results from the simulation are summarized and displayed as a box-and-whisker plot. Such a plot al- lows a fairly straight-forward visual presentation of the statistical distribution of a data set, and is a valuable graphical method to compare the distribution of two separate data sets (Fig. 4).

\subsection{Simulated sediment erosion rates}

Catchment-wide erosion rates from the 46 catchments tracked in the model allow comparison of the statistical distributions between CRN-derived and volumetrically averaged erosion rates for each of the nine simulations, and illustrate variations in the statistical distributions within each simulation as a function of catchment order (Fig. 5).

Several conclusions can be drawn from these data. First, with increasing proportion of sediment detachment, the CRN-determined erosion rate at any catchment scale more closely reflects the volumetric erosion rate for any given total combined erosion rate (Fig. 6). This is not unexpected, as sediment detachment is modeled as a uniformly continuous process in the simulation, such that increased ratios of sediment detachment-to-landsliding will result in a greater contribution from a steady-state process to the overall erosional volume. (It is worth noting that under this formulation, for any given total erosion rate, an increase in sediment detachment rate results in a decrease in the rate of erosion due to landsliding. This, increasing the rate of sediment detachment CRN-derived erosion rates that are closer to the volumetric erosion rates, but further from the total erosion rate due the reduction in frequency of landslides; Fig. 6). Additionally, the data emphasize that the observed magnitude-frequency relationships of landslides skew volumetric erosion towards the larger, more infrequent, landslides [14,15]. This is reflected in all nine simulations, where the median $50 \%$ of the CRN-derived and volumetric erosion rates generally fall below the total imposed erosion rate in the simulation. The outer statistical bounds of the $\mathrm{CRN}$-derived and volumetric erosion rates are substantially higher than the imposed erosion rates, reflecting the the infrequency, but importance, of these large events in controlling erosion rates in landslide dominated catchments.

The damping and averaging effect of erosion rates derived from CRNs in sediment are also illustrated in the statistical spread of volumetric- versus CRNderived erosion rates at all catchment scales, sediment 


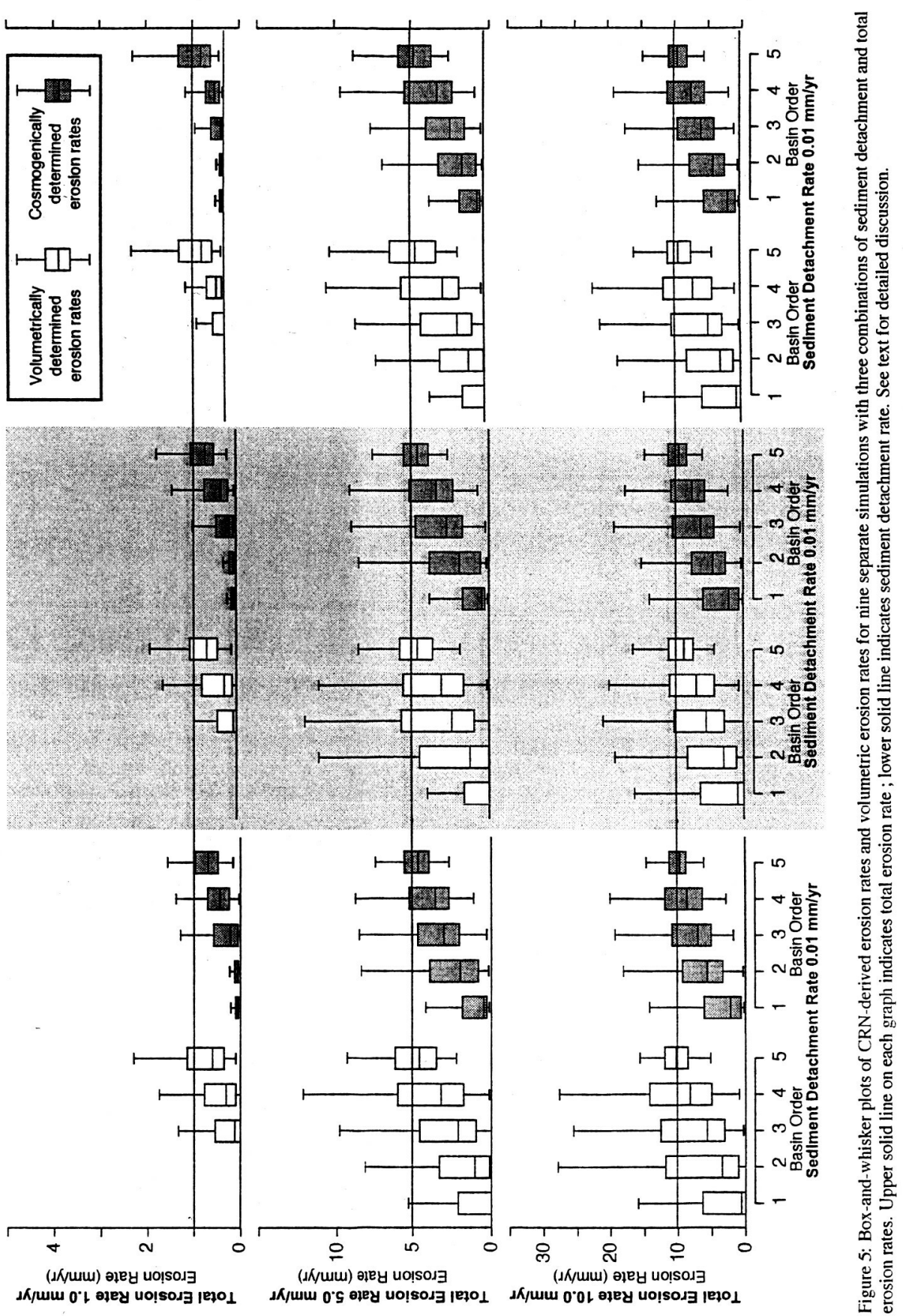


detachment rates, and landslide rates, where the distribution of CRN-derived erosion rates is tighter than contemporaneous volumetric erosion rates. This effect is particularly notable at small to moderate catchment scales in regions with low rates of erosion by landsliding. In particular, at $1 \mathrm{~mm} / \mathrm{yr}$ total erosion rate, the CRN-derived rates have a $50 \%$ smaller distribution than the volumetric erosion rates.

The effect of spatial averaging on the spread of volumetric- and $\mathrm{CRN}$-derived erosion rates is also highlighted in our results (Fig. 5). The statistical spread of both volumetric erosion rates increases with increasing catchment size, presumably related to the increased likelihood of experiencing a large masswasting at greater catchment area, until a threshold is reached, at which point the catchment becomes large enough to adequately average large landsliding events and areas unaffected by mass wasting, and the spread of the data drops significantly. This spatial scale in our simulations appears to occur between fourth- and fifth-order catchments (a jump from $\sim 8 \mathrm{~km}^{2}$ to $\sim 70$ $\mathrm{km}^{2}$ ). The exception to this rule is at low total erosion rates, where landslides appear to occur infrequently enough at all catchment scales to never significantly increase the statistical distribution of erosion rates a third- through fifth-order catchments.

Finally, given the damping and spatial averaging affects described above, it is heartening to note that the median $50 \%$ of observations are more or less consistent between volumetric and $\mathrm{CRN}$-derived erosion rates (Fig. 5). At small catchment scales, CRN-derived rates are typically higher than volumetric rates (this is particularly clear at low total erosion rates), but converge at larger catchment scales (Fig. 6). The catchment size at which this convergence occurs varies, and decreases with increased rates of erosion. As a general rule of thumb, however, it would appear that CRN-derived rates of erosion from sediments are statistically representative of volumetric rates in our numerical simulation at third, or at most, fourth-order catchment scales. This observation indicates that $\mathrm{CRN}$-derived erosion rates from sediments in landslide-dominated catchments may in fact be useful for looking at basin-wide erosion. Even modest-scale drainages, such as San Antonio Creek, have several fourth-order catchments. Measuring CRN-derived erosion rates from each of these catchments should allow the identification of
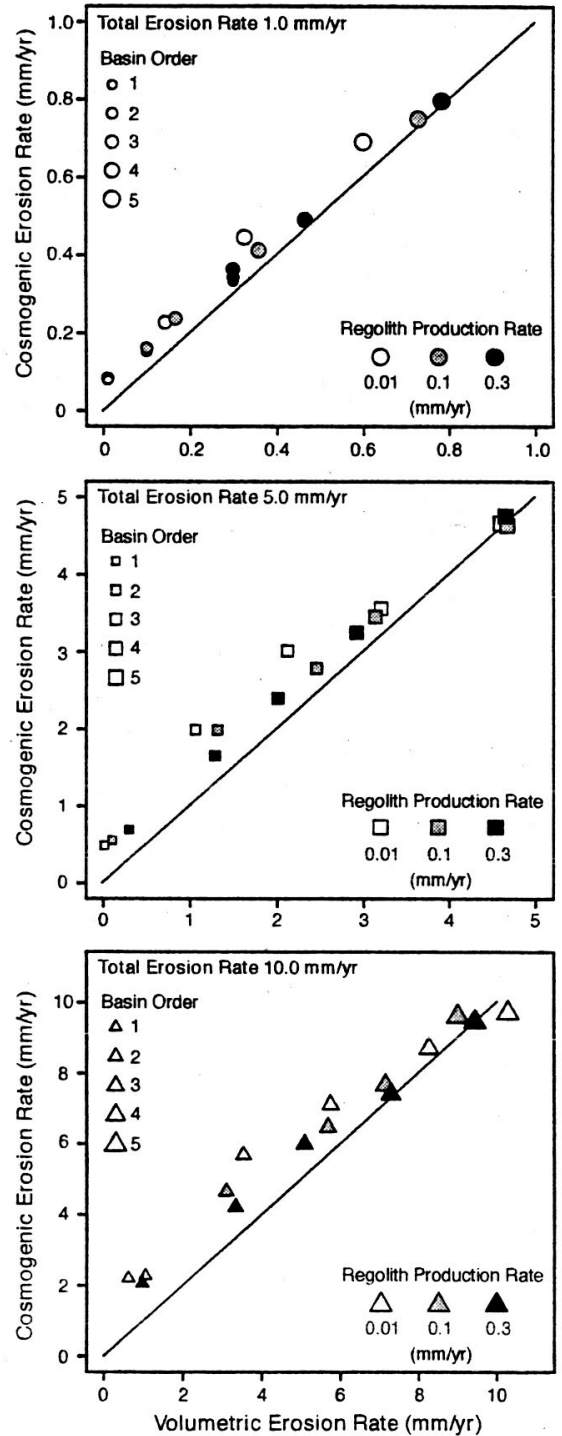

Figure 6. Scatter plots of median cosmogenic versus median volumetric erosion rates for (from top to bottom) total erosion rates of 1 , 5 , and $10 \mathrm{~mm} / \mathrm{yr}$ ). All plots indicate that cosmogenic erosion rates are higher than volumetric erosion rates, and illustrate the convergence of the two rates with increasing sediment detachment rate. 
outlying rates that may be due to recent mass wasting events. Such outlier rates would approximate the recent volumetric erosion rates from the basin (Fig. 5). Nonetheless, even fourth-order catchments are likely to underpredict the overall erosion rate by $20-40 \%$, due to the impact of rare, but unusually large, landslide events.

\subsection{Simulated bedrock erosion rates}

In addition to tracking the $\mathrm{CRN}$ concentration at 46 catchments within the simulation, we also calculated the surface CRN concentration at 100 points randomly distributed throughout the model space, and analyzed such concentrations for erosion rates as though bedrock samples were collected from each of these points (eqn. 4). The statistical distributions of these erosion rates are derived from analysis of 100 random points, sampled 100 times at 1,000 year intervals, over a 100,000 year model run, such that each box-and-whisker in the plot represents the statistical distribution of some 10,000 independently determined erosion rates (Fig. 7).

A first-order observation is that the spread of erosion rates increases with increasing rates of total erosion (and thus, with increasing rates of landsliding). This almost certainly reflects the increased likelihood of any of the randomly sampled points in the model to be affected by landsliding with the increasing frequency of events. A second important observation is that at low rates of total erosion (and landsliding), although sediment detachment encompasses, at most, $30 \%$ of total erosion, the median CRN-derived erosion rate is almost identical to the sediment detachment rate. That is, for any given point in the landscape, the likelihood of sampling a point that has been recently enough effected by mass wasting to alter the CRN concentration is virtually negligible. As the total rate of erosion increases, the median erosion rates increases above the background sediment detachment rate, yet fall well below the total erosion rate over the landscape. In contrast to the distribution of sedimentderived CRN erosion rates (Fig. 5), the upper extent of the 'whisker' ( 3 inter-quartile ranges beyond the median) never exceeds the imposed total erosion rate. Although the CRN-derived erosion rates do not follow a Gaussian distribution, one may draw the analogy that less than $99 \%$ of the 'bedrock' samples will fail to accurately reflect the total erosion rate over the landscape. (The highest actual percentage is $0.25 \%$ for a total erosion rate of $10 \mathrm{~mm} / \mathrm{yr}$, and a sediment detachment rate of $0.01 \mathrm{~mm} / \mathrm{yr}$, where 25 samples out of 10,000 fell within $2 \mathrm{~mm} / \mathrm{yr}$ of the total erosion rate).

These results suggest that sampling bedrock exposures in basins dominated by mass wasting may provide an upper bound on sediment detachment rates across the basin, but are inadequate as a means to derive overall rates of erosion from the combined effects of sediment detachment and landsliding.

\subsection{Response of CRN-derived erosion rates to changes in rates of mass wasting processes}

In addition to tracking the CRN concentrations in sediment from catchments, and at individual points, the simulation also calculates the mean CRN concentration across the landscape at each point in the simulation. Whereas the calculation of CRN and volumetric erosion rates is only performed while the simulation is in an erosional 'steady-state' for the imposed landslide and sediment detachment rates, the mean CRN concentration is calculated throughout the model run to gather an estimate of the response time of CRNs in the landscape to changes in erosional boundary conditions (Fig. 8).

These plots record the mean ${ }^{10} \mathrm{Be}$ concentration over the landscape, beginning at the initialization of the model, where the ${ }^{10} \mathrm{Be}$ concentration at each cell in the simulation is analytically solved for the imposed sediment detachment rate and the scaled production factor at each cell. Subsequently, landslides are populated across the model landscape, and the mean concentration of ${ }^{10} \mathrm{Be}$ begins to decrease at a rate controlled by the sediment detachment rate and the total rate of landsliding imposed on the model. After a period when mean ${ }^{10} \mathrm{Be}$ concentration steadystate is achieved during sediment detachment and landsliding, the landslides are eliminated from the simulation, and the mean ${ }^{10} \mathrm{Be}$ concentration in the landscape increases (Fig. 8A).

Tracking of specific points emphasizes the effects of changes in sediment detachment and landsliding rates on the response time of mean ${ }^{10} \mathrm{Be}$ concentration (Fig. 8B). The response time of the landscape to achieve a new equilibrium mean ${ }^{10} \mathrm{Be}$ concentration is a function of both the sediment detachment rate and the landsliding rate. For a given total ero- 


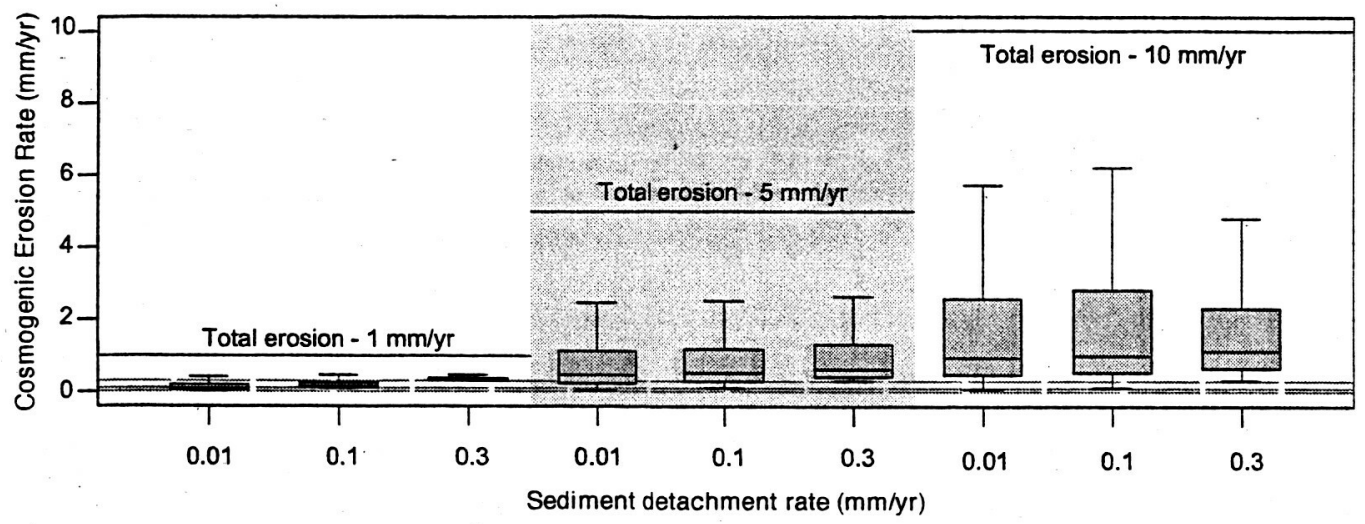

Figure 7. Distribution of cosmogenically determined erosion rates (shaded boxes) from individual sample points for each model run. Total erosion rates for each set of runs are indicated by solid lines; sediment detachment rates are drawn across the lower portion of the graph in dashed lines. As landslide erosion rates increase, the spread and median of cosmogenically derived erosion rates also increase. Median cosmogenically determined erosion rates at these points, however, remain well below total erosion rates for each model run.

sion or sediment detachment rate, the time for ${ }^{10} \mathrm{Be}$ to reach a new equilibrium decreases with an increase in the other rate. Increasing the sediment detachment rate by a factor of ten decreases the time necessary for ${ }^{10} \mathrm{Be}$ to reach a new equilibrium concentration (squares on Fig. 8B); likewise, increasing the rate of landsliding by a factor of 5 causes also yields a decrease in the response time (circles on Fig. 8B). On the other hand, the response time for re-equilibration of mean ${ }^{10} \mathrm{Be}$ concentration at the cessation of landsliding is a function solely of sediment detachment rate. The time necessary for a landscape to recover $95 \%$ of its pre-landslide mean ${ }^{10} \mathrm{Be}$ concentration is as little as 2,000 yrs, at sediment detachment rates of $0.3 \mathrm{~mm} / \mathrm{yr}$, and as great as 55,000 to 75,000 years at sediment detachment rates of $0.01 \mathrm{~mm} / \mathrm{yr}$ (triangles on Fig. 8B).

These results indicate that in rapidly eroding landscapes, changes in landsliding rates over relatively short time periods (say a few thousand years or less) may generate transients in CRN concentrations lasting tens of thousands of years. If landsliding is a more prevalent mechanism of erosion under certain climatic regimes (e.g. during interglacial periods; $[21, ?])$, then the response time of mean ${ }^{10} \mathrm{Be}$ concentration to changes in landsliding rate must be consid- ered when the frequency of these rate changes is of order the ${ }^{10} \mathrm{Be}$ response time of tens of thousands of years.

\subsection{Comparison of simulation results of CRN ero- sion rates to $C R N$ erosion rates from the Nepalese Himalaya}

The Khudi River in Nepal, a tributary to the Marsyandi, has been the focus of a multi-disciplinary study of geomorphic and geodynamic coupling in the Himalaya. As part of this study, erosion rates over this catchment have been assessed using a variety of techniques, including long-term erosion rates from low-temperature thermochronometers $(\geq 2-5 \mathrm{~mm} / \mathrm{yr}$; [22]), and present-day erosion rates from streamsediment suspended-load determinations ( $\sim 3 \mathrm{~mm} / \mathrm{yr}$; E. Gabet, pers. comm.). In addition, ${ }^{10} \mathrm{Be} C R N$ erosion rate determinations were made throughout the catchment, both from bedrock exposures and $0^{\text {th }}$. order $\left(\leq 0.01 \mathrm{~km}^{2}\right)$ catchments, and from the mouth of the Khudi River where it joins the Marsyandi (Heimsath, in prep.). The measured CRN erosion rates were calculated using the same production rates and scaling factors as in the model, and have an average error of $10 \%$. Here we compare the statistical distribution of $56^{10} \mathrm{Be} C R N$ erosion rate determinations from bedrock exposures and $0^{\text {th }}$-order catch- 

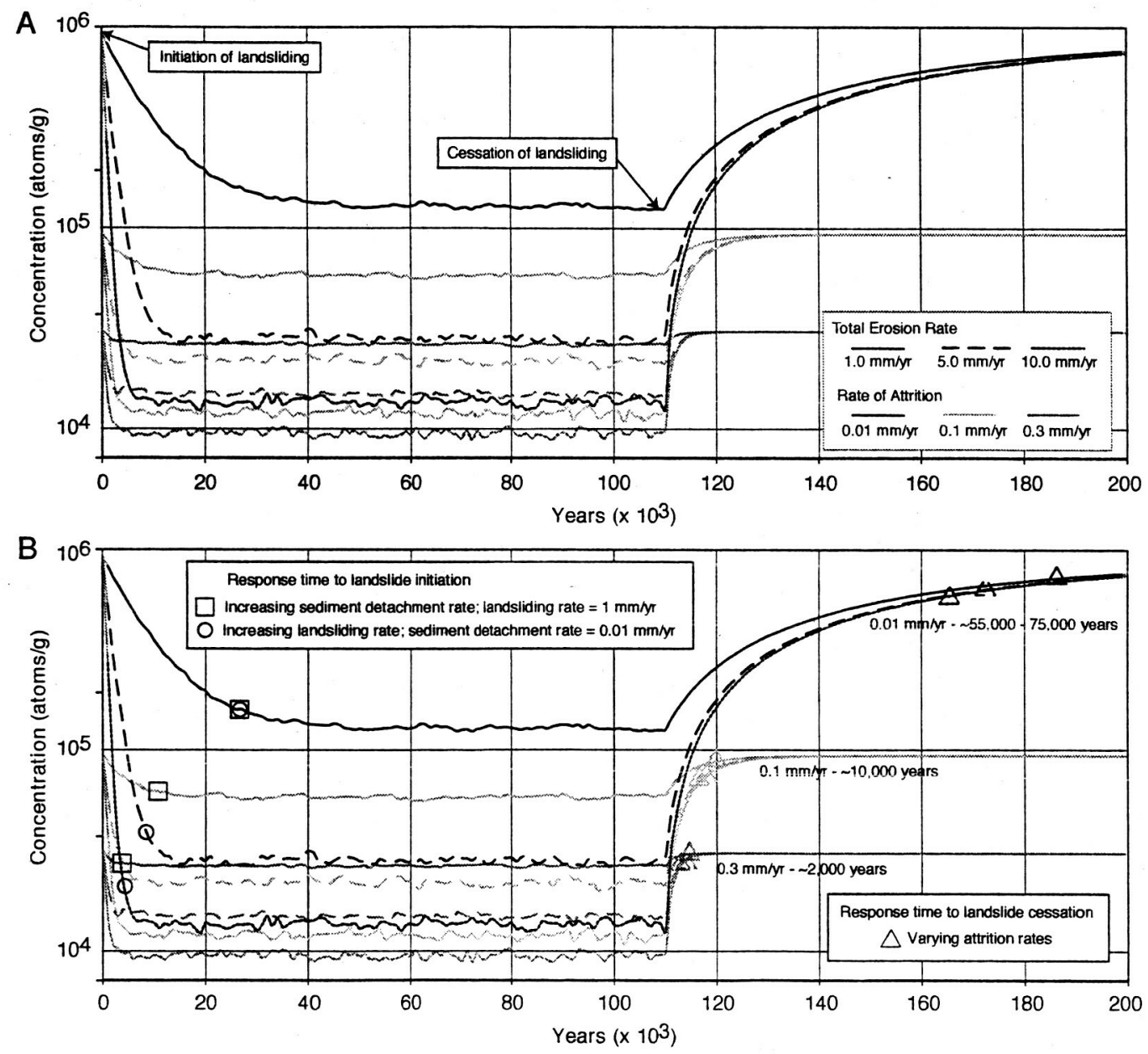

Figure 8. Mean concentration of ${ }^{10} \mathrm{Be}$ across the simulation, showing the effect of initiation and cessation of landslides on ${ }^{10} \mathrm{Be}$ concentration at several different rates of sediment detachment and landsliding. A) Mean ${ }^{10} \mathrm{Be}$ concentration through time for all model runs; initiation and cessation of landsliding indicated. B) Symbols highlighting variation in response time to changing boundary conditions, see text for discussion. 
ments with predicted statistical distributions of CRN erosion rates determined from our simulation. Additionally, we calculate distributions of $\mathrm{CRN}$ erosion rates predicted at the mouth of the Khudi River, and compare these with the basin-wide CRN erosion rates determined for the Khudi catchment.

The simulation of landsliding, cosmogenic production, and erosion was performed as described for the theoretical study in the San Antonio Creek watershed, with only a few modifications. First, the highest resolution DEM available for Nepal has roughly $90-\mathrm{m}$ cell spacing, as opposed to the $30-\mathrm{m}$ spacing available for San Antonio Creek. The model cell size was adjusted accordingly, and the smallest landslide populated in the model was also adjusted to have a radius of 90 meters. Second, available erosion rate data from thermochronologic and sediment-load studies were used to establish a range of landsliding rates to input to the model of the Khudi catchment. A sediment detachment rate of $0.15 \mathrm{~mm} / \mathrm{yr}$ was assumed for the initial model runs, and landsliding rates of $2.85,3.35$, and $3.85 \mathrm{~mm} / \mathrm{yr}$ (for total erosion rates of $3,3.5$, and 4 $\mathrm{mm} / \mathrm{yr}$ ) were selected. The best-fit run was then reanalyzed with varying sediment detachment rates to derive a statistical distribution of bedrock and smallorder catchment CRN erosion rates for comparison with existing CRN data. Finally, the size of the $0 t h$ order catchments is of order the size of the model cell spacing, so these small catchments were treated as points within this model.

\subsubsection{Basin-wide CRN erosion rate in the Khudi catchment}

The distribution of basin-wide CRN-erosion rates derived from the model were compared with a ${ }^{10} \mathrm{Be}$ derived erosion rate measured on sediment deposited at the mouth of the Khudi catchment. The measured CRN erosion rate of $3.4 \mathrm{~mm} / \mathrm{yr}$ matches the median of the CRN erosion rates for the model run with total erosion rate of $3.5 \mathrm{~mm} / \mathrm{yr}(0.15 \mathrm{~mm} / \mathrm{yr}$ sediment detachment and $3.35 \mathrm{~mm} / \mathrm{yr}$ landslides; Fig. 9A). This result supports the theoretical determination that at high landslide erosion rates, the effects of landsliding on CRN erosion rates are spatially averaged over large catchments, and that CRN methods are an effective means of assessing average erosion rates. Further, the median values of each of these three model runs does not overlap the $1^{\text {st }}$ through $3^{\text {rd }}$ quartiles of any other run (Fig. 9A), indicating that the medians of these model runs statistically differ [23]. The results of this simulation, in concert with the actual CRN erosion rate, allow a determination of the erosion rate in the Khudi catchment of $3 \pm 0.5 \mathrm{~mm} / \mathrm{yr}$, tightening the constraints on the erosion rate as derived from thermochronologic and sediment-load data.

\subsubsection{Bedrock and small-order catchment CRN erosion rates in the Khudi catchment}

Using the basin-wide total erosion rate of 3.5 $\mathrm{mm} / \mathrm{yr}$, four additional model runs were executed at increasing rates of sediment detachment $(0.01,0.05$, 0.10 , and $0.15 \mathrm{~mm} / \mathrm{yr}$ ) to compare the simulated distributions of CRN erosion rates with the distribution of $\mathrm{CRN}$ erosion rates determined from $56{ }^{10} \mathrm{Be}$ erosion rates from bedrock samples and $0^{\text {th }}$-order catchments (Heimsath, in prep.; Fig. 9B). In the model space, the same 56 locations that were actually sampled were used to determine a theoretical distribution of bedrock erosion rates. The results of this comparison indicate that, as hypothesized from the theoretical results, sampling bedrock and small area drainage basins for CRN concentrations in regions with significant erosion by bedrock landsliding is not an effective approach to determining basin-wide erosion rates. The data set analyzed in the Khudi drainage is one of the larger CRN erosion rate studies undertaken, yet the number of samples collected, and the percentage of the landscape that they represent, is inadequate to provide a meaningful representation of basin-wide erosional processes. Although thermochronometric, cosmogenic, and sedimentologic techniques all indicate erosion rates in the Khudi of $2-5 \mathrm{~mm} / \mathrm{yr}$, the median CRN erosion rate from the Khudi bedrock samples is $\sim 0.1 \mathrm{~mm} / \mathrm{yr}$, while the median of the simulation runs is $\sim 0.25 \mathrm{~mm} / \mathrm{yr}$ (Fig. 9B). It is also interesting to note that the median erosion rates from the four model runs are very similar, despite an order of magnitude difference in sediment detachment rate among them, and they differ significantly from the median erosion rate determined on the actual bedrock samples. This difference can likely be ascribed to two sources, both due to the fact that the actual bedrock samples from the Khudi catchment almost all came from ridge crests, or small draws that head at ridge crests. The first source of the observed difference is that landslides in the model space are placed ran- 

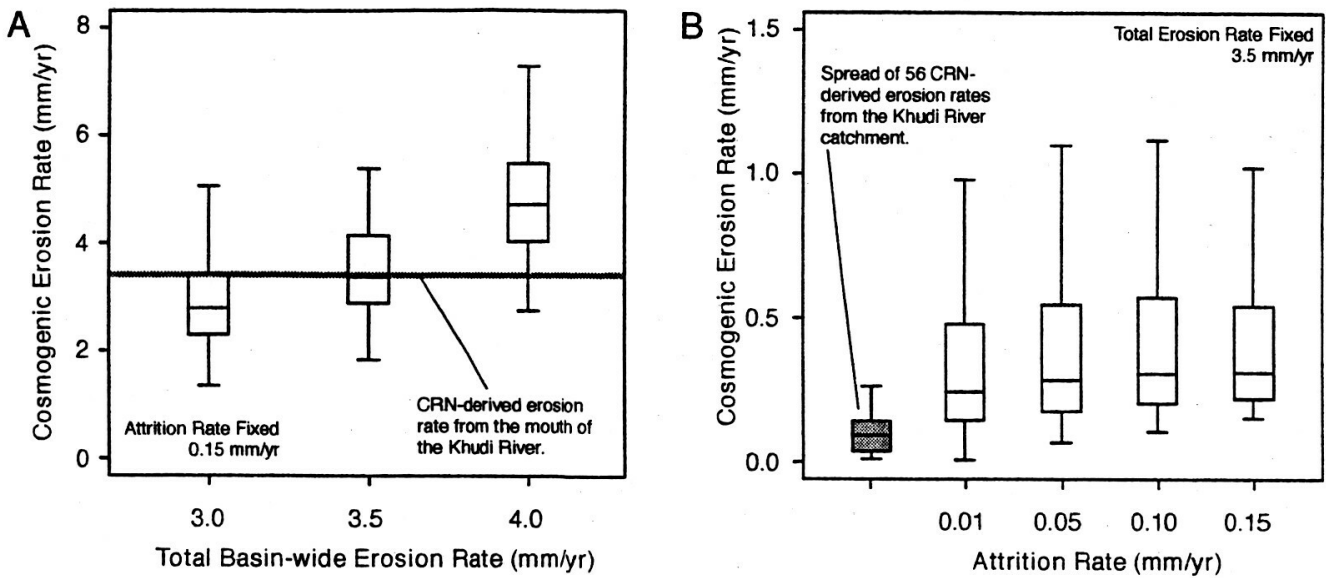

Figure 9. A) Distribution of model basin-wide CRN-derived erosion rates from the mouth of the Khudi drainage for erosion rates of $3.0,3.5$, and $4.0 \mathrm{~mm} / \mathrm{yr}$. The thick gray line across the center of the figure is the measured ${ }^{10} \mathrm{Be}$ derived erosion rate of $3.4 \mathrm{~mm} / \mathrm{yr}$ from the mouth of the Khudi River (A. Heimsath, unpub. data). B) Comparison of simulated distributions of CRN-derived erosion rates from 56 sample locations (white boxes) where actual CRN-erosion rates were measured (gray box; A. Heimsath, unpub. data) for bedrock samples in $0^{t h}$-order catchments in the Khudi drainage. Median CRN erosion rates for both the simulated data and the actual CRN data are an order of magnitude less than the basin-wide erosion rate (A).

domly, such that a ridge crest is as likely to be affected by landslides as a hillslope. In reality, this is likely to not be the case. Landslide mapping indicates that although landslides are preferentially located in areas of steep slopes near the headwaters of drainage systems, such slides rarely breach the drainage divide and lower the interfluve (e.g. [24]). Lowering of drainage divides most plausibly occurs during infrequent events when the topographic slope below the ridge crest has been over steepened by repeated landsliding, and is thus this process is likely to be highly undersampled. The second effect is sampling bias. The CRN samples were specifically collected from bedrock outcrops along the crest that were judged to not have been recently affected by landsliding. As such, the spread of CRN ages would be expected to be smaller than a truly random set of ridge crest samples, and the median erosion rate would, as a result, be lower. This difference notwithstanding, the results of this comparison still serve to emphasize the importance of considering the effects of spatial and temporal averaging in collecting material for CRN determinations of erosion rates in actively landsliding re- gions.

\section{Discussion and Conclusions}

We have presented a numerical simulation for mod eling the production, decay, and distribution of cosmogenic nuclides on a landscape, and their removal through sediment detachment and mass wasting processes. Although this simulation was developed to model the effects of landsliding on $\mathrm{CRN}$-derived erosion rates, the framework of the simulation could be adapted to model any number of factors that effect erosion rates derived from CRNs in sediments, including spatial variations in lithology and mineral content, ice cover, annual snowfall, and recent effects of glaciation. In the past, careful researchers trying to exploit CRNs to obtain erosion rates have commonly restricted their sampling to small, unglaciated catchments with uniform lithologies and slow erosion rates. Variations in CRN production due to topographic shielding, slope, lithology, snow and ice cover, and glacial history have generally been ignored. With the ability to numerically predict the 
effects of such variations, studies can be expanded into larger catchments with higher erosion rates, diverse sediment-production processes, and spatial heterogeneities in CRN concentrations and events that can re-set the cosmogenic clock.

Our landsliding model is underpinned by the observed frequency-magnitude relationships of landslides in two mountain ranges. These happen to yield nearly identical exponential scaling factors $(\beta=$ 1.1) that imply that large, infrequent landslides dominate the total sediment flux. The observation that implementation of our frequency-magnitude based landsliding module yields volumetric rates that oscillate around the expected value suggests that the model succeeds in mimicking a natural process. This frequency-magnitude relationship and the appropriate scaling factor need to be verified in other mountain ranges before they are routinely applied. In addition, we make the implicit assumption that all of the sediment generated by a landslide is delivered and homogeneously mixed with sediment detachment-derived sediment within a single model time step (100 years). We make no attempt to model sediment storage on hillslopes or within fluvial systems, or to model particle size fractionation between sediment detachmentderived and landslide-derived debris.

Our specific evaluation of the effects of bedrock landsliding on erosion rates derived from CRNs using this simulation yielded several results that have been previously described, particularly that stochastic processes, dominated by large rare events, are difficult to measure using basin-averaging sedimentsampling techniques, because the large, rare events, will often not be represented in the sample population (e.g. [?]). However, our simulations also indicate that the median $\mathrm{CRN}$-determined erosion rates are representative of the volumetric erosion rates derived from the same catchments. This suggests that sampling multiple, similarly sized catchments, even in active, landslide-dominated mountain belts, offers a significant likelihood of yielding several samples with consistent $\mathrm{CRN}$ erosion rates. These rates are likely to be representative of the recent erosion within those catchments, although it must be recognized that such results will typically be lower than the longterm average that samples the large, rare events. As long as spatial variations in production can be adequately accounted for, as is done within our model- ing environment, then larger catchments will always yield a better approximation of long-term erosion rate in landslide-dominated terrains than smaller catchments. Although a specific relationship between the catchment size necessary to spatially average CRN samples and erosion rate is difficult to derive, based on our modeling results a general rule of thumb appears to be

$A_{\text {avg }}=\frac{100}{E}$

where $A_{\text {avg }}$ is the area needed to average the variability in CRN concentration, and $E$ is the estimated erosion rate over the catchment.

Sampling from bedrock outcrops to measure average erosion rates in landslide-dominated catchments, however, is unlikely to be a useful exercise. At the low end of landslide erosion rates, such samples will faithfully yield the sediment detachment rate on the landscape, but at increased rates of landslide erosion, such samples will only yield a very rough upper bound on the sediment detachment rate, and, more likely, will be uninterpretable in the context of the spatially averaged erosion rate over the study area.

Finally, the response time of ${ }^{10} \mathrm{Be}$ concentrations over the landscape to changes in rates of erosional processes is thousands to tens of thousands of years. Regions that have undergone recent changes in rates of erosion may yield CRN-derived erosion rates that reflect some intermediate rate between the previous and current erosion rates during the re-establishment of ${ }^{10} \mathrm{Be}$ equilibrium over the landscape.

\section{Acknowledgements}

This work was supported in part by a grant from the Campus-Laboratory Exchange Program of the University of California. Field work in Nepal and analysis of cosmogenic samples were supported by NSF grant EAR-XXXXX. Comments and suggestions from two anonymous reviewers and the editor greatly improved the clarity of this manuscript.

\section{Appendix A}

\section{Governing Equations}

This Appendix details the derivations of three specific portions of the landsiide model, calculating the rate of landsliding, $\kappa$, given a mean landslide erosion 
rate, $E_{l s}$; population of landslides in model space, and determining mean cosmogenic concentration per volume of material removed from the model.

\section{Rate of Landsliding}

We assume that landslides follow a power law frequency magnitude distribution $[7,14]$. For such a distribution, the cumulative frequency of landslides can be written as

$n_{A \geq A_{s}}=\kappa\left(A_{s} / A_{r}\right)^{-\beta} A_{r}$,

where $n_{A \geq A_{s}}$ is the number of landslides greater than area $A_{s}$ that occur in a given year, $A_{r}$ is a specified reference area, $\kappa$ is the rate of landsliding, and $\beta$ is the power-law exponent of the frequency-magnitude distribution [7, see eqn. 1]. If $A_{r}$ is taken to be $1 \mathrm{~km}^{2}$, then from Eqn. A8, the total number of landslides per year, $n$, over the reference area can be written as

$$
\begin{aligned}
n_{r} & =\int_{A_{\min }}^{A_{\max }} \kappa A^{-\beta} d A, \\
& =\kappa\left|A^{-\beta}\right|_{A_{\min }}^{A_{\max }}, \\
& =\kappa\left(A_{\max }^{-\beta}-A_{\min }^{-\beta}\right),
\end{aligned}
$$

where $A_{\min }$ is the area of the smallest landslide to occur in $A_{r}$ (in the case of the simulation, $A_{\min }$ is equal to the model cell size) and $A_{\max }$ is the largest slide area, constrained by local topographic relief. Since $A_{\min }$ and $A_{\max }$ can be constrained either empirically or based on physical characteristics of the model space, and $\beta$ has been shown to be $\sim 1$ over a large range of landslide erosion rates $[7,14,15]$, the volume of material removed by landsliding must be controlled by the rate of landsliding, $\kappa$. Because we would prefer to prescribe a rate of erosion due to landslides, $E_{l s}$ for the model, we need to solve for $\kappa$ in terms of $E_{l s}$. To do this, we start by determining the number of slides, $n_{A_{s}}$, of a given area, $A_{s}$ per year over the reference area, $A_{r}$ :

$n_{A_{s}}=\kappa \beta A_{s}^{-1-\beta}$.

Given this, the volume of erosion in any year due to landslides of area $A_{s}$ is equal to the number of landslides of area $A_{s}$ multiplied by the volume of landslides of area $A_{s}$,

$$
\begin{aligned}
V_{A_{s}} & =n_{A_{s}} \cdot V_{s} \\
& =\kappa \beta A_{s}^{-1-\beta} \cdot V_{s} .
\end{aligned}
$$

In this simulation, we have opted to model the landslides with parabolic cross sections and a linear relationship between maximum slide depth and width $[25,7]$. The scaling between landslide area and depth is defined by a scaling factor, $\varepsilon$, with an empirically determined value of $\sim 0.05$ [7]. Thus, the depth of the landslide, $d$, at any radial distance from the landslide center is a function of the maximum slide depth, the radial distance from the landslide center, $r$, and a constant, $C$,

$d=d_{\max }-C r^{2}$.

We can solve for $C$ at the outer edge of the landslide, $r_{\max }$, where $d=0$,

$C=\frac{d_{\max }}{r_{\max }^{2}}$.

For a slide of a given area $A_{s}$, then, the maximum landslide depth, $d_{\max }$ and radius, $r_{\max }$, are given by

$d_{\max }=\varepsilon \sqrt{A_{s}}$

and

$r_{\max }=\sqrt{\frac{A_{s}}{\pi}}$.

Substitute these values into Eqn. A16 to solve for $C$ in terms of area, $A_{s}$ :

$C=\frac{\varepsilon \sqrt{A_{s}}}{A_{s} / \pi}=\frac{\varepsilon \pi}{\sqrt{A_{s}}}$

and substitute Eqns. A17 and A19 into Eqn. A15 to solve for $d$ as a function of $A_{s}$,

$d=\varepsilon \sqrt{A_{s}}-\frac{\varepsilon \pi}{\sqrt{A_{s}}} r^{2}$.

The volume, $V_{s}$, of a landslide of area $A_{s}$ can then be calculated by integrating over cylindrical shells from $r=0$ to $r_{\max }$,

$$
\begin{aligned}
V_{s} & =2 \pi \int_{0}^{r_{\max }} \varepsilon \sqrt{A_{s}}-\frac{\varepsilon \pi}{\sqrt{A_{s}}} r^{2} \cdot r d r \\
& =2 \pi \varepsilon\left|\frac{\sqrt{A_{s}}}{2} r^{2}-\frac{\pi}{4 \sqrt{A_{s}}} r^{4}\right|_{0}^{\sqrt{A_{s} / \pi}} \\
& =2 \pi \varepsilon\left(\frac{A_{s}^{3 / 2}}{2 \pi}-\frac{A_{s}^{3 / 2}}{4 \pi}\right) \\
& =\frac{\varepsilon}{2} A_{s}^{3 / 2}
\end{aligned}
$$


Eqn. A24 can be substituted back into Eqn. A14 to yield the volume of material, $V_{A_{s}}$, removed from the reference area, $A_{r}$ per year by slides of area $A_{s}$ :

$V_{A_{s}}=\frac{1}{2} \kappa \varepsilon \beta A_{s}^{(1 / 2-\beta)}$.

The total volume of erosion per year from reference area $A_{r}$, then, is the sum of the erosion due to landslides of all sizes that occur in $A_{r}$, from $A_{\min }$ to $A_{\max }$,

$$
\begin{aligned}
V_{r} & =\frac{1}{2} \kappa \varepsilon \beta \int_{A_{\min }}^{A_{\max }} A_{l s}^{(1 / 2-\beta)} d A \\
& =\frac{\kappa \varepsilon \beta}{(3-2 \beta)}\left(A_{\max }^{(3 / 2-\beta)}-A_{\min }^{(3 / 2-\beta)}\right) .
\end{aligned}
$$

The total erosion rate per year due to landslides, then, can be determined by dividing the volume of material eroded per year by landslides over $A_{r}$ by the area of $A_{r}$,

$$
E_{l s}=\frac{V_{r}}{A_{r}}
$$

and, since we have defined $A_{r}$ to be a unit area (1 $\mathrm{km}^{2}$ ),

$$
E_{l s}=V_{r}
$$

Thus, Eqn. A27 can be solved for $\kappa$ in terms of $E_{l s}$ to yield

$\kappa=\frac{E_{l s}(3-2 \beta)}{\varepsilon \beta\left(A_{\max }^{(3 / 2-\beta)}-A_{\min }^{(3 / 2-\beta)}\right)}$.

Substituting Eqn. A30 into Eqn. A11 yields the total number of landslides, $n_{r}$, per year over the reference area, $A_{r}$ in terms of known or prescribed values $A_{\min }, A_{\max }, \beta, \varepsilon$, and $E_{l s}$ :

$n_{r}=\frac{E_{l s}(3-2 \beta)\left(A_{\max }^{-\beta}-A_{\min }^{-\beta}\right)}{\varepsilon \beta\left(A_{\max }^{(3 / 2-\beta)}-A_{\min }^{(3 / 2-\beta)}\right)}$

The total number of landslides, $n_{l s}$, then, in the simulation for a given time step, $t$, over the entire simulation is

$n_{l s}=t \times n_{r} \times \frac{A_{s i m}}{A_{r}}$

where $A_{\text {sim }}$ is the area, in $\mathrm{km}^{2}$, of the simulation.

\section{Landslide Population and Distribution}

With the number of landslides per time step determined, the simulation is populated. The position each landslide is specified by a randomly generated $\mathrm{x}, \mathrm{y}$ coordinate pair. The size of a given landslide is derived from the landslide frequency-magnitude relationship (Eqn. A8). The probability of a landslide with area $A_{s}$ occurring is

$$
\mathrm{P}_{A_{s}}=\kappa A_{s}^{-\beta}
$$

therefore, randomly generated numbers mapped linearly onto the range $\mathrm{P}_{A_{\min }}$ to $\mathrm{P}_{A_{\max }}$ can be used to create a population of $n_{l s}$ landslides that fit the frequency-magnitude distribution $\kappa A^{-\beta}$.

\section{Cosmogenic Nuclide Concentration in Eroded Ma- terial}

For each model step, the total depth of material removed from a given cell, $D$, is the sum of material eroded by sediment detachment, $E_{s}$ and the material eroded by landslides, $E_{l s}$. Using the surface concentration of a cosmogenic nuclide at the end of the model step, $N_{f}^{10} \mathrm{Be}$, the average nuclide concentration in the volume of eroded material, $N_{D}^{10} \mathrm{Be}$ can be calculated by integrating over the total depth of eroded material the concentration of the nuclide as a function of e-folding depth, $\Lambda$,

$$
\begin{aligned}
N_{D}^{10} \mathrm{Be} & =N_{f}^{10} \mathrm{Be} \cdot \rho \int_{-D}^{0} e^{-z(\rho / \Lambda)} d z \\
& =N_{f}^{10} \mathrm{Be} \cdot \rho \cdot \frac{\Lambda}{\rho}\left|-e^{-z(\rho / \Lambda)}\right|_{-D}^{0} \\
& =N_{f}^{10} \mathrm{Be} \cdot \Lambda\left(e^{D(\rho / \Lambda)}-1\right)
\end{aligned}
$$

\section{REFERENCES}

1. P. Molnar, P. England, Late Cenozoic uplift of mountain ranges and global climate change: Chicken or egg?, Nature 346 (1990) 29-34.

2. E. T. Brown, R. F. Stallard, M. C. Larsen, G. M. Raisbeck, F. Yiou, Denudation rates determined from the accumulation of in situ-produced ${ }^{10} \mathrm{Be}$ in the Luquillo experimental forest, Puerto Rico, Earth Planet. Sci. Lett. 129 (1-4) (1995) 193-202.

3. P. Bierman, E. J. Steig, Estimating rates of denudation using cosmogenic isotope abundances in sediment, Earth Surface Processes and Landforms 21 (1996) 125-139. 
4. D. E. Granger, J. W. Kirchner, R. Finkel, Spatially averaged long-term erosion rates measured from in situ-produced cosmogenic nuclides in alluvial sediments, J. Geol. 104 (3) (1996) 249-257.

5. E. M. Clapp, P. R. Bierman, A. P. Schick, J. Lekach, Y. Enzel, M. Caffee, Sediment yield exceeds sediment production in arid region drainage basins, Geology 28 (2000) 995-998.

6. C. S. Riebe, J. W. Kirchner, D. E. Granger, R. C. Finkel, Erosional equilibrium and disequilibrium in the Sierra Nevada, inferred from cosmogenic ${ }^{26} \mathrm{Al}$ and ${ }^{10} \mathrm{Be}$ in alluvial sediment, Geology 28 (9) (2000) 803-806.

7. N. Hovius, C. P. Stark, P. A. Allen, Sediment flux from a mountain belt derived by landslide mapping, Geology 25 (3) (1997) 231-234.

8. S. A. Binnie, J. A. Spotila, W. M. Phillips, M. A. Summerfield, K. A. Fifield, The coexistence of steady and non-steady state topography in the San Bernardino Mountains, southern California, from cosmogenic ${ }^{10} \mathrm{Be}$ and $\mathrm{U}-\mathrm{Th} / \mathrm{He}$ thermochronology, Geol. Soc. Am., Abstr. Prog. 35.

9. T. J. Dunai, Scaling factors for production rates of in situ produced cosmogenic nuclides; a critical reevaluation, Earth Planet. Sci. Lett. 176 (1) (2000) 157-169.

10. T. J. Dunai, Erratum to Scaling factors for production rates of in situ produced cosmogenic nuclides; a critical reevaluation, Earth Planet. Sci. Lett. $178(2000) 425$.

11. A. Dunne, D. Elmore, P. Muzikar, Scaling factors for the rates of production of cosmogenic nuclides for geometric shielding and attenuation at depth on sloped surfaces, Geomorphology 27 (12) (1999) 3-11.

12. J. Masarik, R. C. Reedy, Terrestrial cosmogenicnuclide production systematics calculated from numerical simulations, Earth Planet. Sci. Lett. $136(3-4)$ (1995) 381-395.

13. A. Heimsath, The soil production function, $\mathrm{Ph} . \mathrm{D}$., University of California (1999).

14. C. P. Stark, N. Hovius, The characterization of landslide size distributions, Geophys. Res. Lett. 28 (6) (2001) 1091-1094.

15. J. Lavé, D. Burbank, Denudation processes and rates in the Transverse Ranges, Southern California; erosional response of a transitional landscape to external and anthropogenic forcing, J.
Geophys. Res. 109 (1) (2004) 31.

16. D. Lal, Cosmic ray labeling of erosion surfaces; in situ nuclide production rates and erosion models, Earth Planet. Sci. Lett. 104 (2-4) (1991) 424 439.

17. A. E. Blythe, D. W. Burbank, K. A. Farley, E. J. Fielding, Structural and topographic evolution of the central Transverse Ranges, California, from apatite fission-track, (U-Th)/He and digital elevation model analyses, Basin Research 12 (2) (2000) 97-114.

18. A. E. Blythe, M. A. House, J. A. Spotila, Low-temperature thermochronology of the San Gabriel and San Bernardino mountains, southern California; constraining structural evolution, in: A. Barth (Ed.), Contributions to Crustal Evolution of the Southwestern United States, Special Paper 365, Geological Society of America, 2002, pp. 231-250.

19. J. A. Spotila, M. A. House, A. E. Blythe, N. A. Niemi, G. C. Bank, Controls on the erosion and geomorphic evolution of the San Bernardino and San Gabriel mountains, southern California, in: A. Barth (Ed.), Contributions to Crustal Evolution of the Southwestern United States, Special Paper 365, Geological Society of America, 2002, pp. 205-230.

20. D. M. Morton, F. K. Miller, Preliminary geologic map of the San Bernardino $30^{\prime} \times 60^{\prime}$ quadrangle, California, Open-file Report 03-293, U. S. Geological Survey, 2003.

21. M. Julian, E. Anthony, Aspects of landslide activity in the Mercantour massif and the French Riviera, southeastern France, Geomorphology 15 (1996) 175-289.

22. D. W. Burbank, A. E. Blythe, J. Putkonen, B. Pratt-Sitaula, E. Gabet, M. Oskin, A. Barros, T. P. Ojha, Decoupling of erosion and precipitation in the Himalayas, Nature 426 (6967) (2003) 652-655.

23. J. M. Chambers, W. S. Cleveland, B. Kleiner, P. A. Tukey, Graphical Methods for Data Analysis, Wadsworth, 1983.

24. J.-c. Chang, O. Slaymaker, Frequency and spatial distribution of landslides in a mountainous drainage basin: Western Foothills, Taiwan, Catena 46 (2002) 285-307.

25. H. Ohmori, Morphological characteristics of the 
scar created by large-scale rapid mass movement, Chike $=$ Transactions - Japanese Geomorphological Union 13 (3) (1992) 185-202. 